\title{
In vivo observations of skin capillaries in workers exposed to vinyl chloride. An English-American comparison
}

\author{
H. R. MARICQ, ${ }^{1}$ C. S. DARKE, ${ }^{2}$ R. MCL. ARCHIBALD, ${ }^{3}$ AND E. C. LEROY \\ From the ${ }^{1,4}$ Medical University of South Carolina, Charleston, South Carolina, USA, the ${ }^{2}$ Royal \\ Infirmary, Sheffield, England, and the ${ }^{3}$ National Coal Board, London, England
}

ABSTRACT An unselected sample of vinyl chloride (VC)-exposed individuals, all employees of a polyvinyl chloride production plant in England (129 subjects), were examined by in vivo capillary microscopy. Results were compared with those previously obtained from a similar study in the USA to determine whether an association between VC exposure and capillary abnormalities could be found in different environments. The results showed a similar distribution of capillary abnormalities among the VC workers in both countries $(39.5 \%$ in England compared with $36 \%$ in the USA). These capillary abnormalities were significantly more frequent among VC-exposed subjects than among control industrial workers $(7 \cdot 7 \%, 6 \%$. In vivo microscopy also showed a higher incidence of papular lesions $(13.5 \%)$ than had been detected clinically $(1 \%)$.

Our previous survey of 152 polyvinyl chloride (PVC) production workers in the United States of America demonstrated that $36 \%$ had skin capillary abnormalities visible by in vivo microscopy compared with $6 \%$ in control manual workers (Maricq et al., 1976). In $14 \%$, capillary abnormalities were scattered, similar to those in scleroderma (SD); in the remaining $22 \%$ only isolated capillary changes were seen. Workers suffering from vinyl chloride (VC)-related disease had more capillary abnormalities than had other employees of the PVC industry. Because reports from different countries have shown a great variability in the prevalence and type of VCrelated disease (Chatelain and Motillon, 1967; Byrén and Holmberg, 1975; Duck et al., 1975; Lilis et al., 1975; Sakabe, 1975; Suciu, 1975; Thiess and Frentzel-Beyme, 1975; Veltman et al., 1975), the presence of capillary abnormalities in VC-exposed subjects from a different country was determined. Results were similar to those found previously in the USA.

\section{Methods}

SUBJECTS

The VC-exposed population consisted of all 129 employees, 126 men and 3 women, of a PVC pro-

Received for publication 2 June 1977

Accepted for publication 2 August 1977 duction plant in England. They were 18-64 years old (mean age $40.9 \mathrm{yr}$ ). Independent clinical assessments concerning VC-related disease were available for 104 of these subjects. Control subjects comprised 26 employees of another (non-PVC-producing) chemical plant located in the same industrial complex. Although these controls were not exposed to VC in their place of employment, VC exposure from the outside environment was possible. They were all men, 19-64 years old (mean áge $41 \cdot 9 \mathrm{yr}$ ).

WIDE-FIELD CAPILLARY MICROSCOPY

The hands of all subjects were examined by widefield capillary microscopy as previously described (Maricq et al., 1976). Twelve standard sites were examined in each subject, four nailfolds and two each of the following sites: dorsum of the distal phalanx other than the nailfold, dorsum of the middle phalanx, dorsum of the proximal interphalangeal joint, and the finger pad. Examination by direct observation was complemented by photographs (Maricq, 1970) coded for blind analysis.

\section{SKIN EXAMINATION}

The skin of both hands was surveyed for papular lesions by gross and microscopic examinations.

CLINICAL ASSESSMENT

Subjects were classified by independent clinical assessment as severely affected, affected, or not 


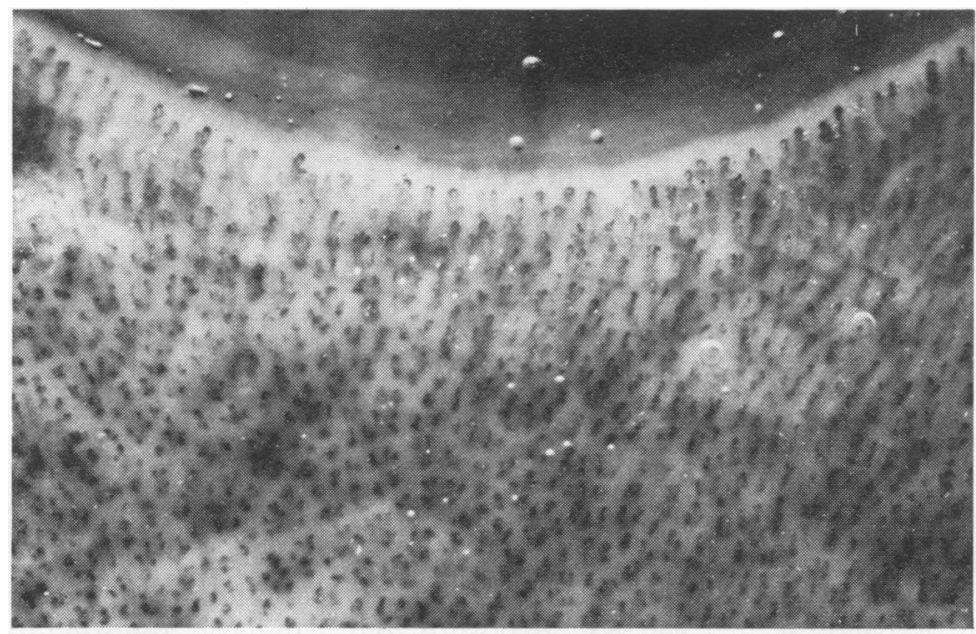

(a)

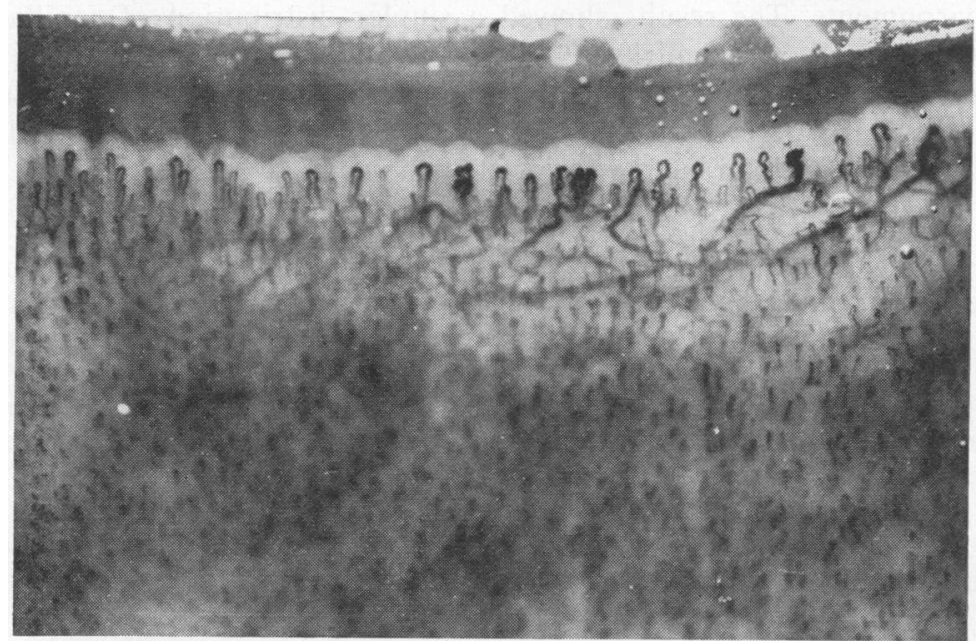

(b)

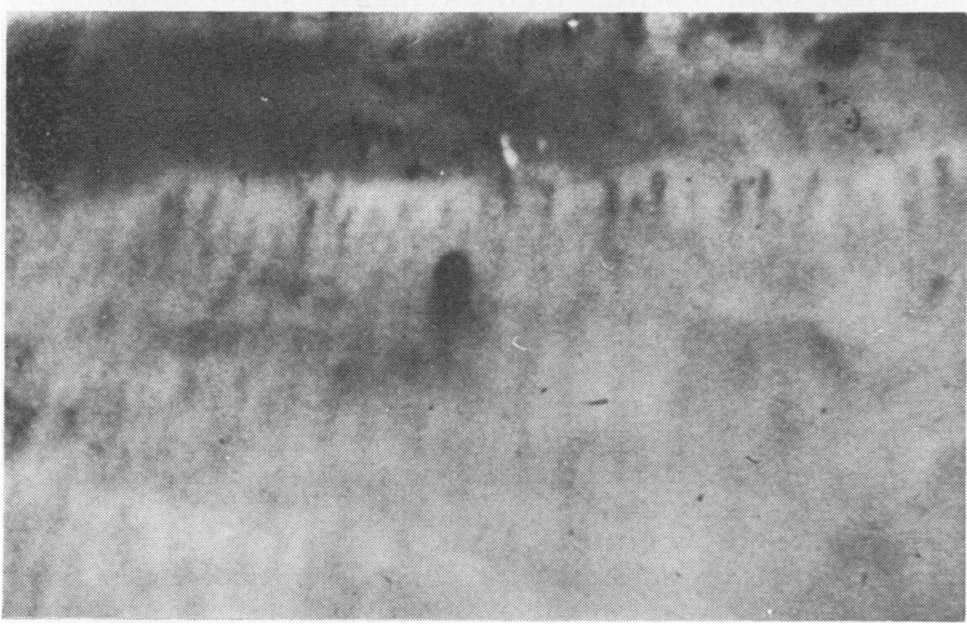

(c)

Fig. 1 (a) View of the nailfold and of the dorsum of the distal phalanx in a normal subject. (b) Several abnormally large capillaries in the nailfold of a $V C$ worker. (c) An isolated large capillary on the dorsum of the finger in a VC-exposed subject. (Copyright 1976, American Medical Association.) 


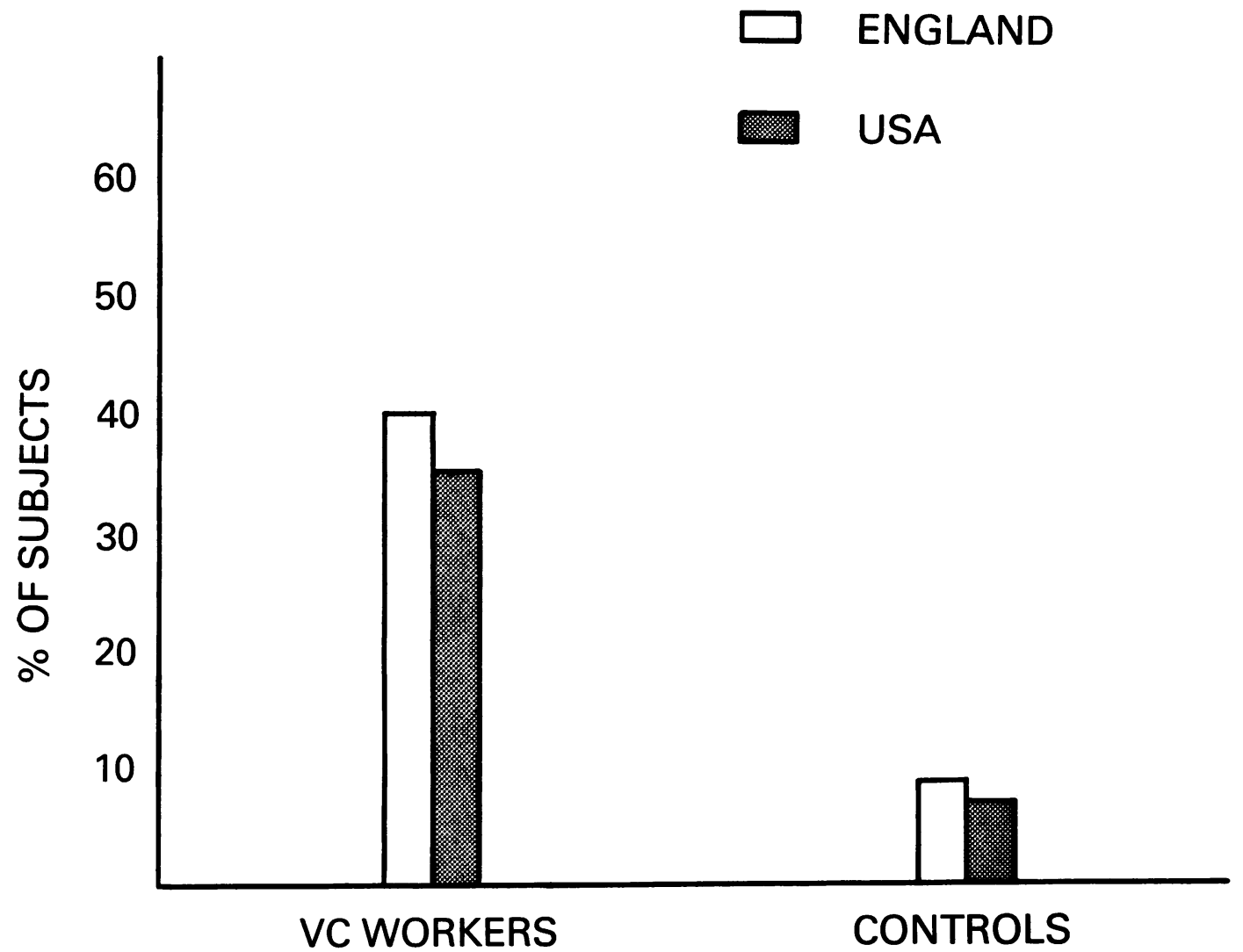

Fig. 2 Frequency of capillary abnormalities in VC-exposed subjects in England and in the USA.

affected. Among 104 employees, 26 were affected or severely affected, most of whom had symptoms and signs in the hands. Twenty-five had Raynaud's syndrome; of these, 15 presented with numbness, tingling, weakness, and stiffness of the fingers, and eight with the same symptoms in the hands and feet. Eight subjects complained of stiffness and aches and pains in the knees, elbows, lower legs, and back. Nine had signs and symptoms of pulmonary dysfunction. There was one subject with nodular skin lesions and one with acro-osteolysis, but no documented cases of hepatic fibrosis or angiosarcoma. In 14 subjects, sites other than the hands were involved. The results of the clinical assessment were not known to the examiners at the time of the capillary observations.

\section{WORK HISTORY}

Information was also obtained on the following aspects of subjects' past history: length of employment with the company, number of years spent as reactor cleaners and the type of occupation at the time of the examination. For those workers who were off duty because of possible VC-related conditions the duration of absence from work was recorded. This information was filed for later analysis and was not known to those who performed the capillary examinations.

\section{Results}

\section{CAPILLARY MICROSCOPY}

Capillary abnormalities (Fig. 1) in this study were similar to those previously reported from the USA (Fig. 2) (Maricq et al., 1976), and were significantly more frequent among PVC production plant employees $(39.5 \%)$ than among nearby chemical workers $(7.7 \%$, Table 1$)$. Scattered capillary abnormalities were present in $17 \%$ of VC-exposed subjects and isolated capillary changes in an additional $22.5 \%$. These results were confirmed by analysis of coded photographs.

In the VC-exposed group, subjects were divided into two categories by clinical assessment. Affected 
Table 1 Comparison of capillary observations in $P V C$ and chemical plant employees

\begin{tabular}{lllll}
\hline Observations & \multicolumn{2}{l}{ Type of plant } & \multirow{2}{*}{$x^{2}$} & $P$ \\
\cline { 2 - 3 } & PVC & Chemical & & \\
\hline $\begin{array}{c}\text { Scattered capillary } \\
\text { abnormalities }\end{array}$ & 22 & 2 & & \\
$\begin{array}{c}\text { Isolated capillary } \\
\text { abnormalities }\end{array}$ & 29 & 0 & 10.40 & $<0.01$ \\
$\begin{array}{c}\text { No capillary } \\
\text { abnormalities }\end{array}$ & 78 & 24 & & \\
\hline
\end{tabular}

and severely affected employees were combined into a symptomatic group and compared with the nonaffected or asymptomatic group. The results demonstrated a statistically significant difference $\left(\chi^{2}\right.$ with 2 degrees of freedom $=10.84 ; \mathrm{P}<0.01$ ) in the prevalence of capillary abnormalities between the symptomatic and asymptomatic subjects (Table 2). Asymptomatic workers had significantly more
Table 2 Distribution of capillary abnormalities among subjects according to clinical assessment

\begin{tabular}{lllll}
\hline Observations & Symptomatic & Asymptomatic & $x^{2}$ & $P$ \\
\hline $\begin{array}{c}\text { Scattered capillary } \\
\text { abnormalities }\end{array}$ & 10 & 8 & & \\
$\begin{array}{c}\text { Isolated capillary } \\
\text { abnormalities }\end{array}$ & 5 & 22 & 10.84 & $<0.01$ \\
$\begin{array}{c}\text { No capillary } \\
\text { abnormalities }\end{array}$ & 11 & 48 & & \\
\hline
\end{tabular}

capillary abnormalities than controls ( $\chi^{2}$ with 2 degrees of freedom $=10.13 ; \mathrm{P}<0.01$ ).

Scattered capillary abnormalities were most frequent among the symptomatic workers; isolated capillary changes among the asymptomatic ones. Comparison of results from England and the USA shows a similar correlation of capillary abnormalities with clinical status in both countries (Fig. 3). In both

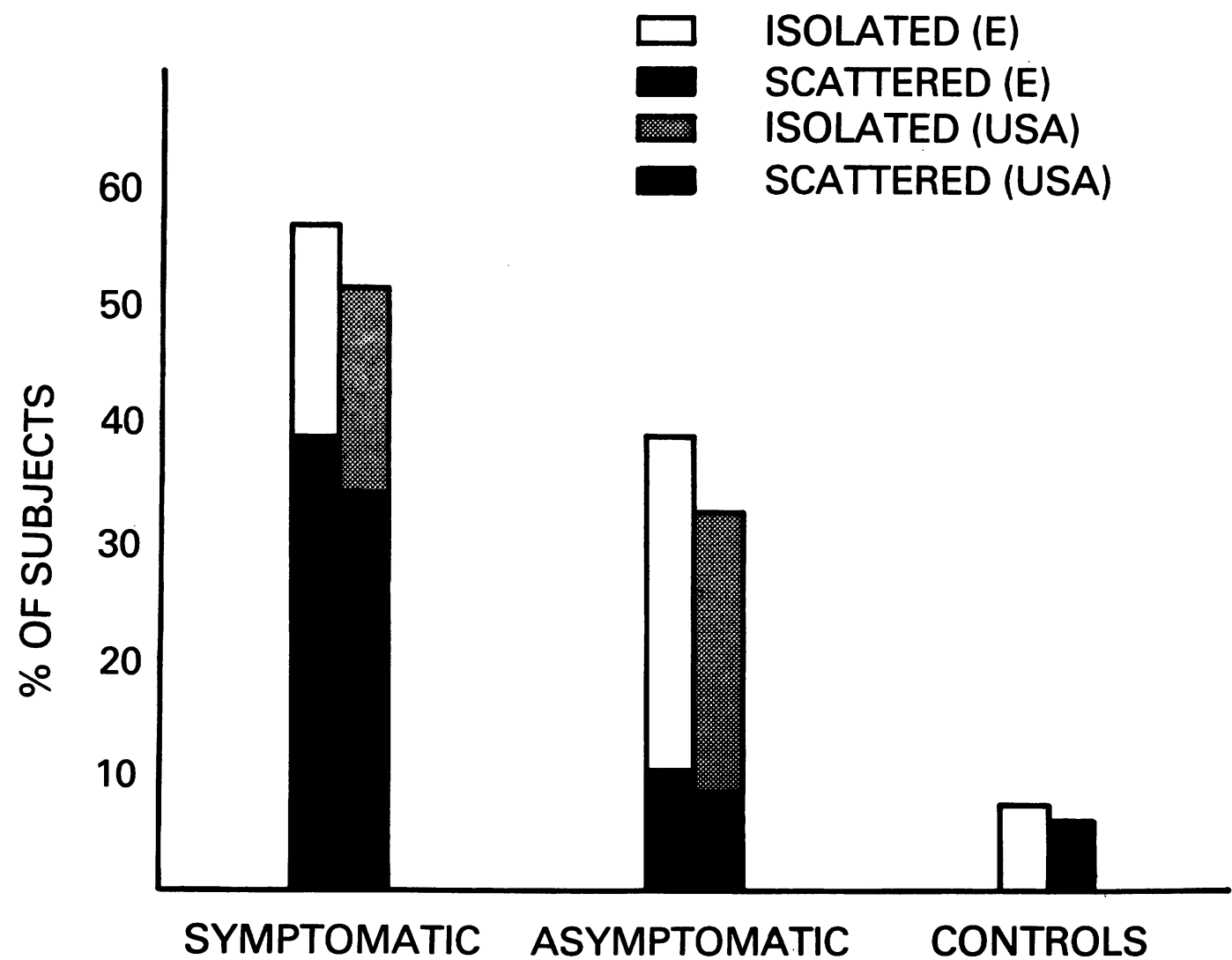

Fig. 3 Comparison of the type of capillary abnormalities in the two countries. 
studies the majority of symptomatic workers have shown capillary abnormalities.

As in our previous study of workers in the USA, no correlation was found between the length of employment or the length of time spent as reactor cleaner and the presence of capillary abnormalities. (The mean number of years with the company was 3.8 (SD $\pm 2.2 \mathrm{yr}$ ) and the reactor experience 1.1 years (SD $\pm 0.7 \mathrm{yr}$ ) for the workers in the present study). The type of employment at the time of this examination did not appear to have any relationship to the capillary findings, nor was there any correlation between the capillary abnormalities and the age of the subjects.

At the time of the examination, 15 workers had not been working at the plant for periods ranging from six months to two years. There was no evidence of any relationship between the presence or absence of capillary abnormalities and the length of such absence from the plant.

\section{PAPULAR LESIONS}

As well as the large, papular, scleroderma-like skin changes similar to those reported in the literature and already noted by previous examiners of these workers, we also observed smaller, faintly visible papular lesions (Fig. 4a). The smallest of these papules (minipapules) were seen better when examined under the microscope (Fig. 4b). The proportion of subjects with such papular lesions was also significantly different in the three groups studied (Fig. 5) $\left(\chi^{2}\right.$ with 2 degrees of freedom $=20.07$; $P$ $<0.0005)$. The numbers of subjects with scattered capillary abnormalities and papular lesions were comparable; of 22 patients with papular lesions and/or scattered capillary abnormalities, eight had both.

\section{Discussion}

The results of this study show that capillary abnormalities are present in VC-exposed individuals to the same degree in two different countries, England and the USA, indicating that such microvascular changes are probably not influenced by differences in manufacturing procedures or environmental factors from country to country.

The fact that the American sample included more severely affected symptomatic patients and that the duration of possible VC exposure was longer (mean length of employment 15 years versus 3.8 years) than in the group of English workers, while the prevalence of capillary abnormalities was comparable in both countries, suggests that capillary abnormalities may precede more serious VC-related disorders.

The prevalence of capillary abnormalities among

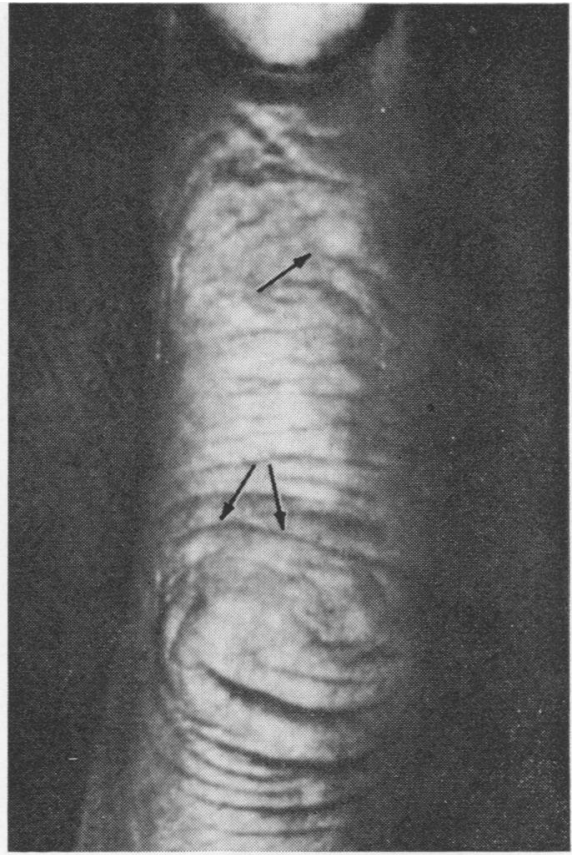

(a)

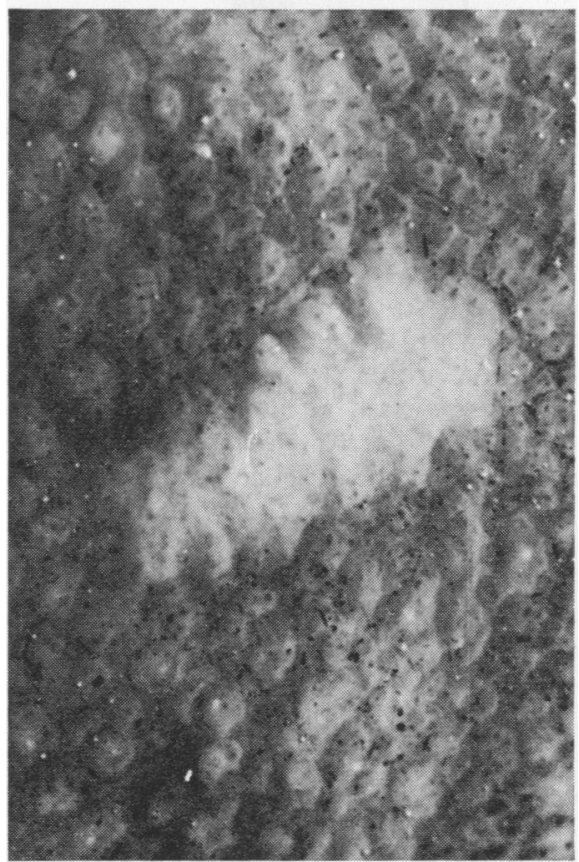

(b)

Fig. 4 (a) Small papular lesions on the dorsum of the finger in a VC worker. (b) Microscopic appearance of $a$ minipapule. (Copyright 1976, American Medical Association.) 


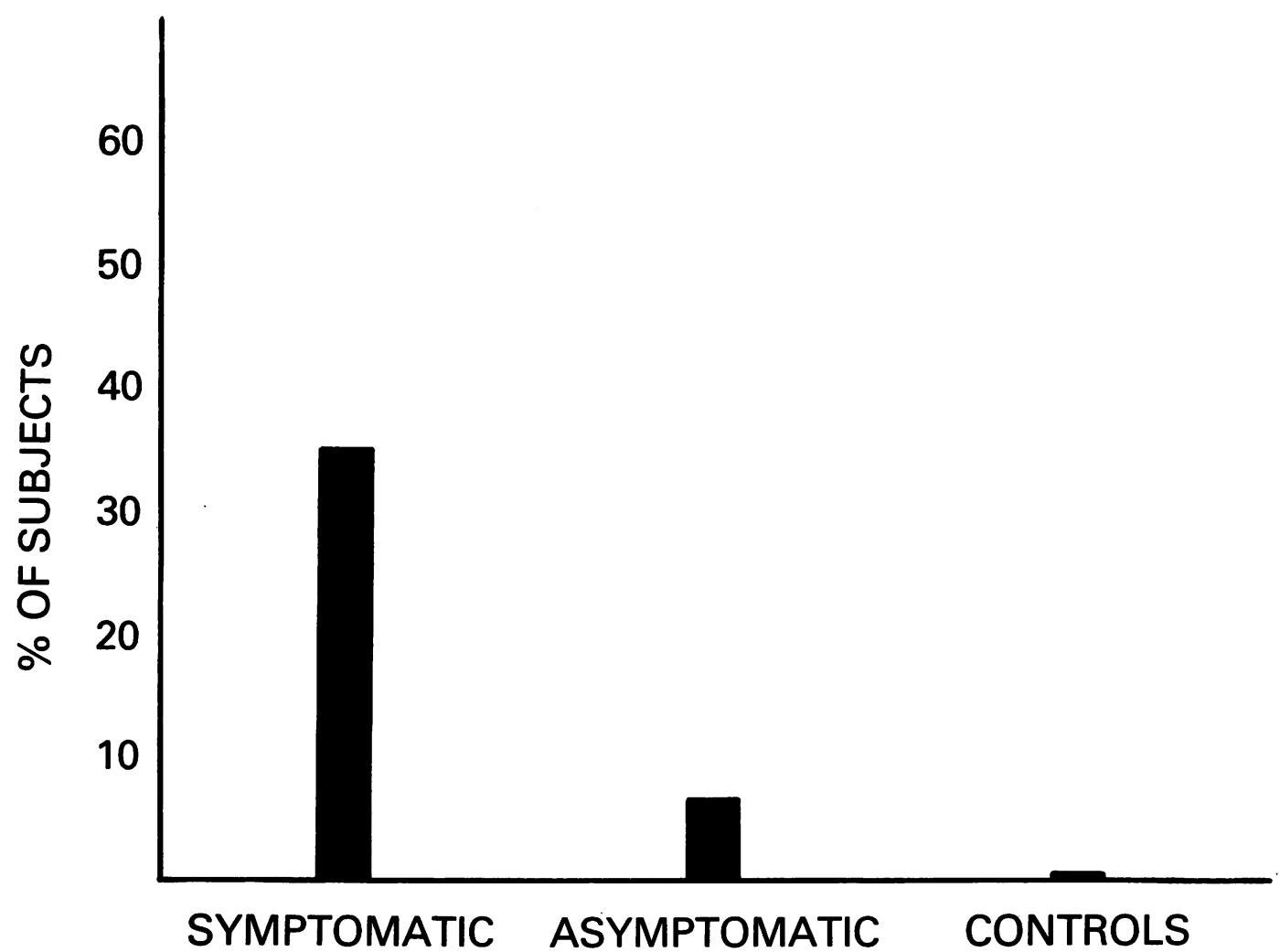

Fig. 5 Frequency of papular lesions among the study subjects.

workers who had ceased to have contact with VC was not less than that among those who were still working at the plant. Although there was no obvious correlation with the length of cessation of VC exposure, the group is small; furthermore all 15 belong to the clinically affected group and it is therefore difficult to determine whether capillary abnormalities would be reversible or not, at least in some cases.

As few PVC workers develop progressive VCrelated disease, some even after being removed from VC-exposure, while more appear to suffer transient and reversible effects and most show no apparent ill effect even after years of VC-exposure, it is postulated that a genetic predisposition may be involved in VC-related disease and in the associated capillary abnormalities. Genetic predisposition may vary from country to country because of different gene pools. However, no information on this subject was expected from the present investigation because most of the American workers were of Anglo-Saxon origin.

The results of this study have thus confirmed, on an unselected sample of VC-exposed individuals, the relationship of skin capillary abnormalities with VC exposure and VC-related conditions. Further work is necessary to explore the nature of this relationship, as well as the relationship of VC exposure to papular skin lesions.

This investigation was supported in part by the Sidney and Charlotte Lifschultz Foundation, the National Institute of Health grant AM 18904, the South Carolina Appropriation to the Medical University for General Medical and Faculty Research, the RGK Foundation, Continental Oil Company Medical Division and Chemicals Division, and Vinatex Limited. The technical assistance of Karen Menth, James Menth, and Joyce Hardin is hereby gratefully acknowledged. We would also like to thank the American Medical Association for permission to use Figures $1 \mathrm{c}$ and $4 \mathrm{~b}$ which were previously used in a slightly different form as Figure 3 of our article entitled 'Capillary Abnormalities in Polyvinyl Chloride Production Workers', which appeared in the Journal of the American Medical Association, September 20, 1976, 236, 1368-1371. 


\section{References}

Byrén, D., and Holmberg, B. (1975). Two possible cases of angio-sarcoma of the liver in a group of Swedish vinyl chloride-polyvinyl chloride workers. Annals of the New York Academy of Sciences, 246, 249-250.

Chatelain, A., and Motillon, P. (1967). Un syndrome d'acro-ostéolyse d'origine professionelle et de constatation nouvelle en France. Journal de Radiologie, d'Electrologie et de Médecine Nucleaire, 48, 277-280.

Duck, B. W., Carter, J. T., and Coombes, E. J. (1975) Mortality study of workers in a polyvinyl-chloride production plant. Lancet, 2, 1197-1199.

Lilis, R., Anderson, H., Nicholson, W. J., Dawn, S., Fischbein, A. S., and Selikoff, I. J. (1975). Prevalence of disease among vinyl chloride and polyvinyl chloride workers. Annals of the New York Academy of Sciences, 246, 22-41.

Maricq, H. R. (1970). Wide-field photography of nailfold capillary bed and a scale of plexus visualization scores
(PVS). Microvascular Research, 2, 335-340.

Marica, H. R., Johnson, M. N., Whetstone, C. L., and LeRoy, E. C. (1976). Capillary abnormalities in polyvinyl chloride production workers. Examination by in vivo microscopy. Journal of the American Medical Association, 236, 1368-1371.

Sakabe, H. (1975). Bone lesions among polyvinyl chloride production workers in Japan. Annals of the New York Academy of Sciences, 246, 78-79.

Suciu, I., Prodnan, L., Ilea, E., Păduraru, A., and Pascu, L. (1975). Clinical manifestations in vinyl chloride poisoning. Annals of the New York Academy of Sciences, 246, 53-69. Thiess, A. M., and Frentzel-Beyme, R. (1975). Retrospective survey of the alleged diseases associated with vinyl-chloride in the Federal Republic of Germany. Journal of Occupational Medicine, 17, 430-432.

Veltman, G., Lange, C. E., Jühe, S., Stein, G., and Bachner, U. (1975). Clinical manifestations and course of vinyl chloride disease. Annals of the New York Academy of Sciences, 246, 6-17. 